\title{
Interactive comment on "Contrasting exhumation histories and relief development within the Three Rivers Region (Southeast Tibet)" by Xiong Ou et al.
}

\section{Paolo Ballato (Referee)}

paolo.ballato@uniroma3.it

Received and published: 4 November 2020

I am pleased to review the manuscript "Contrasting exhumation histories and relief development within the Three Rivers Region (SE Tibet)" by Xiong OU et al., which presents a set of 3D thermo-kinematic models to unravel the exhumation, tectonic and topographic history of two adjacent areas exhibiting a different topographic and cooling age pattern. Specifically, the Kagawebo massif is characterized by high topographic relief and very young cooling ages, while the BaimaXuexhan massif has slightly older cooling ages and is part of a system of elevated low-relief surfaces described all around SE Tibet. By testing different modeling scenarios, the authors document variations in 
rock uplift rate trough time, the role of tectonic deformation, the influence of climate change and the impact of fluvial incision (the Mekong river) in controlling the observed cooling patterns.

I am not familiar with the 3D thermo-kinematic modeling, therefore, I assume that is formally correct and the selection of the modeling parameters is appropriate. Overall, the manuscript is well structured, clearly written and brings important structural and geomorphic conclusions (that probably are not properly emphasized, see comments below) and hence I believe that will be of interest for the entire scientific community. I have just few minor concerns that I think should be addressed.

1) A major assumption presented in the introduction is that the low-relief surface of the BaimaXueshan massif is part of a system of elevated low-relief surfaces observed all around SE Tibet, like that one in the Daocheng area. Is that initial assumption really correct? I think that the authors should provide a set of figures (a DEM with topographic swath profiles), to document the validity of such assumption (see also comments on line 36 , Lines 366-368, and on figure 8 among others). The figures provided in this version (mostly Figure 1), seem to suggest that the low-relief landscape of the BaimaXueshan massif is different from that one of the Daocheng area. If you cannot document it, you will have to rewrite part of the introduction and the conclusions.

2) From my understanding the authors rule out the classic idea where the low-relief patches were part of the same surface that formed at low elevation and has not yet adjusted to the new rock uplift rate (see Clark and Royden), while fluvial incision should have started right after surface uplift. I think that this should be properly emphasized because it has also major geodynamic implications (for example it does not support the lower crustal flow hypothesis, or?). Following these lines: does your study add new data/constraints on the vertical and lateral growth of the Tibetan Plateau? In case, please discuss it.

3) The contribution of the incision of the Mekong river over the estimated exhumation 
for both massifs should be better discussed. How did you get that estimate? In case, a swath profile across the Mekong will help to figure it out (see also comment above).

4) The erosional processes that led to the removal of ca. $2.5 \mathrm{~km}$ of rocks on top of the BaimaXueshan massif should be also better discussed and documented with a figure (see comments on Line 371-379). The authors mention the occurrence of landforms associated with glacial processes that I think should be documented in a figure (at least on a DEM) to strengthen their conclusions. I also think that there is an issue of time scales: rock uplift accelerated at ca. $10 \mathrm{Ma}$, while vigorous glacial erosion started only at $2 \mathrm{Ma}$. How do you reconcile this lag-time between uplift and erosion?

I hope my comment will be of help. Good job!

Line by line comments:

Lines 18-20: I think that in the abstract you should suggest what could be the cause for rock uplift and Neogene exhumation for the BaimaXuexhan massif.

Line 25. What depth (see also few comments below)?

Line 36: How do you define low-relief surfaces? You should define what kind of relief threshold you use for a low-relief surface (at least to a first order) and document it by showing a proper DEM (please see also comment on Figure 1). This probably applies also to the abstract (line 20) where the low-relief surface is mentioned for the first time.

Line 51: "However, the direct link between river incision and regional tectonic uplift that is inherent in this interpretation has been disputed (Liu-Zeng et al., 2008; 2018; Nie et al., 2018)". I think you should comment this sentence here in introduction. What has been disputed and why? Please consider, that not all readers are familiar with the debate. I guess that this is fundamental for framing your research question.

Line 61: In such regard, I think that you should already highlight in the introduction that Nie et al., interpreted the cooling pattern observed across the Mekong as an increase in precipitation rather than an indication of surface uplift (although that study is based

Printer-friendly version

Discussion paper
Interactive

comment

3 
on samples collected further south, so the correlation may not be straightforward)

Line 100: I think that you should highlight all these differences by showing a E-Woriented topographic swath profile across the Mekong and its flanks (BaimaXuexhan and Kawagebo). This is fundamental to properly quantify river incision (which I guess has been discussed and quantified in several papers, but readers should not be forced to look for old literature unless strictly necessary). You can provide easily such a figure. I also think that you should present a N-S topographic swath profile (see also comment to line 36 and to figure 8 ).

Line 107: "In contrast, no clear estimation for the age of plateau uplift in the Three Rivers Region has been obtained" In contrast to what? In the previous sentences the uplift of the plateau is not discussed. I think that a summary about our knowledge of surface uplift/paleo-elevation history of the SE Tibetan Plateau should be reported somewhere. This kind of information is completely missing in the manuscript but is fundamental for setting up your modeling scenarios.

Line 108: Please show the location of the Jianchuan basin in a figure.

Line 181: Can you model a scenario consisting of a low-relied surface at low elevation, uplifted and incised at the same time (see for example Clark and Royden 2000)? I guess that should be something like your "incision" scenario but with surface uplift., where the low-relief areas are assumed to represent a landscape that has not yet adjusted to the new rock uplift rate. Or do you think that available thermochron. data do not support any longer this idea? I think that your study may contribute to this debate.

Line 182: You assume that at $10 \mathrm{Ma}$ there was already a plateau with an elevation like the modern one. Can you quickly report what data are supporting this scenario?

Line 188: What does crustal-scale mean? Please clarify it. After reading the beginning of the following section I realized that the crustal scale fault scenario was used only 
for the Kawagebo Massif. I am wondering if you should anticipate this in the methods (where you talk about a generic fault) in order to provide a complete picture of the modeling scenarios (maybe the 6 lines of text at the beginning of the results section could go directly in the methods?).

Line 240: not clear to me how you quantified river incision (same applies to line 313).

Line 354-350: Long sentence. Difficult to follow. Please rewrite it

Line 360-370: I guess that this is a very important finding and tell us that the classic view (formation of low-relief surfaces at low elevation that will be uplifted and incised) decays. Should that be highlighted more? Unless the two surface are not the same object as I start suspecting (please see comment on Figure 8 and below).

Lines 366-368: "Therefore, the BaimaXueshan massif cannot be considered to represent the same relict surface as the Daocheng granite, despite the fact that both have low relief (Fig. 1)". Following my previous comments: do they really have a similar topographic relief to be considered the same object, as written in the introduction? Maybe you should also present a NE-SW topographic swath profile that cover both regions and discuss it. The relief map shown in Figure 1c does not really suggests it. I can see that the BaimaXueshan is sandwiched between 2 main rivers, so its preservation potential is lower, but your Figure 1c seems to suggest that these two features look very different.

Line 371-379: "Such buzzsaw-like processes by glaciation could be active in the BaimaXueshan massif to smooth highlands, as numerous cirques, moraines and Ushaped valleys are observed across the massif, providing evidence for significant glacial erosion". The erosional mechanisms that can remove ca. $2.5 \mathrm{~km}$ of rocks and generate elevated low-relief surfaces are a crucial issue. Although this is not the main point of the manuscript the conclusions of this work have important geomorphologic implications. I think that the authors should provide a figure (probably just a DEM) documenting the glacial morphologies described in the text, or at least they should refer 
to previous publications documenting the processes (in Tibet or elsewhere) that may have generated such a topography. The other point that I think needs to be addressed is the timing of these erosional processes that should post-date (at least for 8 Million of years) the onset of widespread high-altitude glaciations (ca. $2 \mathrm{Ma}$ ). Does it mean that first you formed a much higher topography and later you removed the material without any additional, significant cooling? In case, could you document it with yours 3D thermo-kinematic models?

Line 428: "which flattens at depth" What depth? Can you provide estimates? Could they correspond to any specific rock boundary?

Figure 1B: What is the benefit of showing a Landsat image rather than a DEM? Frankly speaking I do not find such a Landasat image useful, especially, if you are not familiar with the region. The scale of figure 1a does not allow appreciating the topographic characteristics and the position of the paleosurfaces. I guess that you need to use a DEM as background of figure $1 \mathrm{~A}$. Especially after reading the conclusion for the BaimaXueshan massif. I also think that you need some topographic swath profiles (see comments above).

Figure 2: I am sorry, but my eyes cannot really differentiate the Triassic Qiangtang from the Yidin. Could you please increase the color difference? Also note that some black lines are thicker, apparently without any specific reason, than others. Finally, Eocene is not properly spelled; please correct it. What about showing a simplified cross section? Are there available in literature? They could help following the geological setting.

Table 2: Does the sketch has a vertical scale that I respected? What is the level of incision with respect to the initial plateau? This should be discussed somewhere (see comment to line 240) to better appreciate the contribution of the Mekong on the observed cooling history.

Figure 5: What are the modeling shortening rates over the last $1.5 \mathrm{Ma}$ for the Kawagebo massif? Are these rates compatible with the lateral shearing rates recorded 


\section{by GPS?}

Figure 8: From this figure the low-relief surface of the BaimaXueshan massif does not

look like a typical uplifted low-relief landscape (please see also my comments above). I think that a clear definition of low-relief surface is fundamental. To me the landscape of the BaimaXueshan massif and the Daocheng area looks totally different and the large difference in cooling ages observed across these 2 surfaces is not surprising. I also suppose that the erosional mechanism that led to the development of these "surfaces" is very different (glacial vs fluvial?) and operated on different time scales. I start thinking that you are comparing surfaces that should not be compared. Such a comparison is misleading because these two surfaces are not the same landform. I understand that this is one of your major conclusions; my concern is that your starting point (i.e., these 2 surfaces are the same thing) does not appear to be supported by geomorphic evidence, unless you will document with a couple of figures.

Interactive comment on Solid Earth Discuss., https://doi.org/10.5194/se-2020-172, 2020. 